\title{
New records of Diptera Chamaemyiidae from the Mediterranean and Oman with a description of a new species: Parochthiphila (Euestelia) argentiseta from Turkey and a redescription of Parochthiphila (Parochthiphila) inconstans (Becker)
}

\author{
Alfio Raspi \& Martin J. Ebejer
}

Raspi, A. \& Ebejer, M. J. 2008: New records of Diptera Chamaemyiidae from the Mediterranean and Oman with a description of a new species: Parochthiphila (Euestelia) argentiseta from Turkey and a redescription of Parochthiphila (Parochthiphila) inconstans (Becker). — Entomol. Fennica 19: 55-64.

A new species of Chamaemyiidae from Turkey, Parochthiphila (Euestelia) argentiseta is described. Parochthiphila inconstans (Becker, 1903) is assigned to the subgenus Parochthiphila Czerny, 1904 after examination of the types. New records of 25 species are given from several countries around the Mediterranean and from Oman thus extending our previously scant knowledge of the distribution of these species of flies particularly in the Mediterranean.

A. Raspi, Department of Tree Science, Entomology and Plant Pathology "G. Scaramuzzi" of Pisa University. Section of Agricultural Entomology, Via S. Michele degli Scalzi, 2, 56124 Pisa, Italy;E-mail: araspi@agr.unipi.it M.J. Ebejer, Amgueddfa Cymru National Museum Wales, Cathays Park, Cardiff, United Kingdom CF10 3NP; E-mail: martin.ebejer@btinternet.com

Received 11 May 2007, accepted 6 August 2007

\section{Introduction}

The Chamaemyiidae is a family of small flies found in all zoogeographic areas. The species, during their larval stages, are predators of Aphidoidea and/or Coccoidea and adults as well as larvae can be commonly found at appropriate locations when large populations of their hosts occur. Although some species have been found very infrequently, many are widespread and common. In spite of this, records from many Mediterranean countries and from countries of the Middle East are sparse or entirely lacking, thus leaving wide gaps in knowledge of their distribution and ecology.

In this article we report some of our records based on material obtained recently in Oman and in a number of countries around the Mediterranean. We report only records that are new to the countries concerned. We have been unable to identify all species encountered, usually because no male specimens are available. There are no published records of Chamaemyiidae from Malta or from Oman and particular efforts were made to identify all material from these two countries. A search through Zoological Record and through the Fauna Europaea database (Gaimari 2007) confirmed that our records are new for the countries listed. It is not the scope of this article to review what is already known about Chamaemyiidae in each of the countries for which we are adding new records. 
A number of species of Chamaemyiidae are listed in the catalogues of the Diptera of Spain (Carles-Tolrá 2002) and of Italy (Raspi 1995). In this article we add new records to the Balearic Islands of Ibiza and Mallorca and to Italy (Liguria, Tuscany and Sicily). Beschovski and Merz (1998) reported their records of species from Croatia, France, Israel, Italy and Switzerland. They were the first to record L. formosana Hennig, 1938 from the Mediterranean (Israel).

Tanasijtshuk (1986), who studied the Types of $P$. inconstans, placed this species in the subgenus Euestelia Enderlein, 1927. However, one of us (AR) borrowed and re-examined the Types. It can be confirmed with certainty that they in fact do have a mesopleural seta and correctly belong to the subgenus Parochthiphila Czerny, 1904, as quoted by Frey (1958). This species is redescribed and illustrated in order to clarify its taxonomic characters.

\section{Redescription of Parochthiphila (Parochthiphila) inconstans (Becker, 1903) (Figs 1-4)}

Redescription. Lectotype $\widehat{\sigma}$ and $2+9+$ Paralectotypes, Siala, Egypt; additional specimens

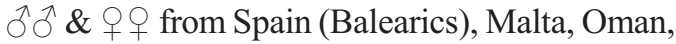
Tunisia.

Diagnosis. Body light silvery grey. Mesopleuron with single strong seta. Frons pale matt grey, at level of anterior orbital seta, only in female with a transverse band of black pollinosity. Antenna yellow-brown. Mesonotum, 1 presutural and 2 strong, posteriorly located, dorsocentral setae. Abdomen of male and female with 2 pairs, 2 median and 2 lateral, suboval, elongate black spots on tergites 3-5 and 3-6 respectively. Tibiae and tarsi yellow; hind tibiae with a narrow inconspicuous dark ring close to base.

Description. of \& 9 . Length: $2-3 \mathrm{~mm}$ (The types are about $3 \mathrm{~mm}$, excluding the antennae). Body light silvery grey, with a faint reddish-gold dusting on abdomen, sometimes also with golden dusting on thorax and more thinly on frons.

Head. About 1.3 times higher than long; frons at level of anterior ocellus 0.4 times width of head. Frons pale matt grey, at level of anterior or-
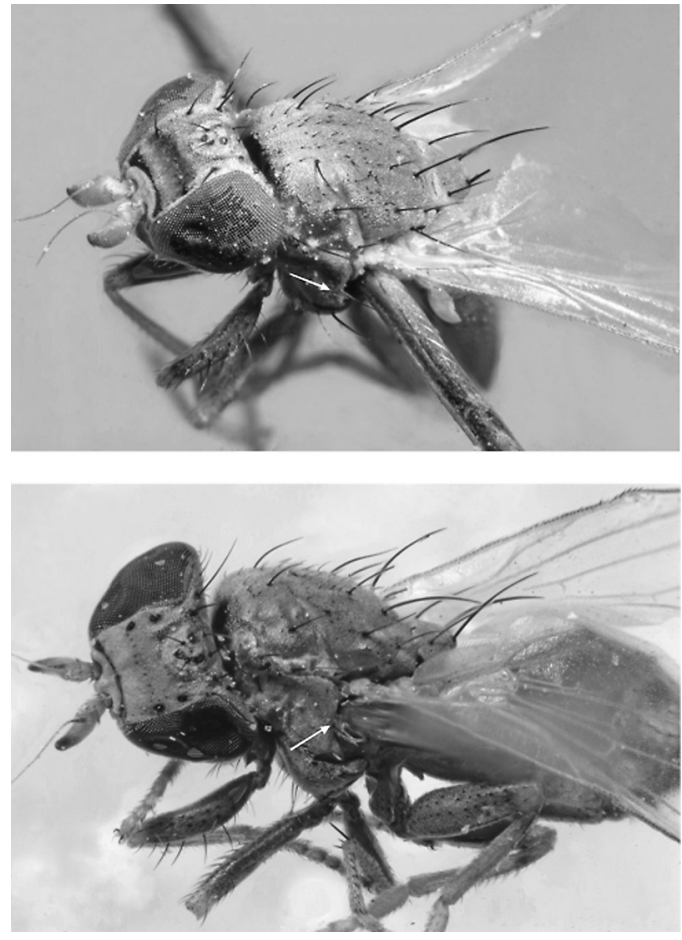

Fig. 1. Parochthiphila (Parochthiphila) inconstans (Becker), Malta. Female (top), detail of frons, with a broad transverse band of black pollinosity, and thorax; male (bottom), detail of frons and thorax. The white arrow points to the mesopleural seta.

bital seta with transverse irregular rows of scattered setulae and, only in the female, a broad transverse band of black pollinosity (Fig. 1). Usually a dark brown-black band above border of lunule almost reaching eyes, more evident in female. Lunule bare, grey, semi-elliptical. Between base of the antennae, a prominent grey facial carina reaching fronto-clypeal suture. Ocellar plate silvery grey and slightly raised; ocelli about equidistant. Chaetotaxy: 2 reclinate orbital setae, the anterior not quite reaching anterior third of frons. Ocellar setae proclinate, inner vertical seta shorter than outer vertical seta, postocellar setae small and convergent. Antenna yellow-brown, arising beneath middle of head. First flagellomere yellow, elongate, with pointed apex which is dark brown to black, 1.6 times as long as high and with longer and more visible white hairs on upper border. Pedicel light brown pruinose on inner part, yellow on external part. Arista: first segment yellowish, second light brown like basal part of 
third, becoming paler distally, third segment 5-7 times as long as second. Gena in profile about 0.3 height of eye. Short genal setulae present. Palp and labellum yellow.

Thorax (Fig.1). Mesonotum grey, rarely with two inconspicuous short dark grey pollinose median vittae. Chaetotaxy: 1 humeral, 1 posthumeral, 1 anterior notopleural which is about twice length of 1 posterior notopleural, 1 presutural supra-alar, 1 supra-alar, 1 postalar, 1 posterior intra-alar, $1+2$ dorsocentrals, posterior 2 placed far behind suture, middle seta approximately half length of posterior; acrostichal setulae in 4 irregular rows anteriorly and in 2 rows between hind dorsocentrals, sometimes a small setula before the presutural dorsocentral seta; no prescutellar setae present. Prescutellum developed. Scutellum uniformly silver grey pollinose with 1 pair of basal setae half length of subapical pair. Mesopleuron (Fig. 1) with a strong seta at middle of posterior margin; sternopleuron with single strong seta preceded by 2 setulae along upper edge.

Wing. Hyaline with pale yellow microtrichia. Veins pale yellow except for $\mathrm{R} 2+3$, which is pale brown throughout its length, contrasting with the other pale veins. Anterior crossvein at or just beyond middle of discal cell. Veins $\mathrm{R}_{4+5}$ and $\mathrm{M}_{1+2}$ parallel in distal half. Apical section of $\mathrm{CuA} 1$ about as long as posterior crossvein; $\mathrm{CuA} 1$ not reaching border of wing. Haltere pale yellow.

Legs. Femora dark grey; apical 1/6 of femora, whole of tibiae and tarsi yellow. Hind tibiae with a narrow dark ring at base, barely visible.

Abdomen. Grey, with a light reddish gold pollinosity. Male and female with 2 pairs ( 2 median and 2 lateral) of suboval, elongate, black spots on tergites 3-5 and 3-6 respectively. First median pair sometimes poorly visible. Tergites 3-5 covered with sparse setulae, arranged in about four irregular transverse rows, longer and stronger at postero-lateral angles and along posterior edge.

Male terminalia (Fig. 2). Pregenital sclerites: 2 separate sclerites present dorsally between fifth tergite and epandrium, sixth tergite transversally narrow and elongated, sub-rectangular, sixth sternum mostly membranous, only 2 symmetrical sub-oval very small and weak sclerites, barely visible; syntergosternite $7+8$ more or less forms
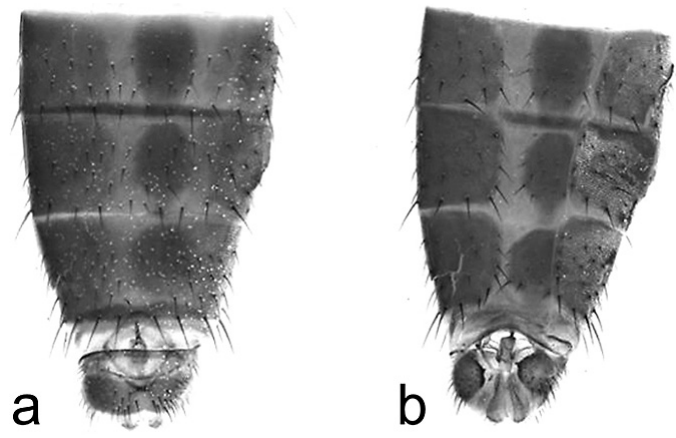

Fig. 2. Parochthiphila (Parochthiphila) inconstans (Becker), Malta. Male terminalia. - a. Dorsal view. -b. Ventral view.

a ring, more sclerotized dorsally particularly along margin; largely membranous ventrally except for narrow margin along the upper edge. Epandrium (Fig. 3) sub-rectangular in lateral view, about twice as high as wide, with many strong setae. Aedeagal apodeme sub-triangular, small and slender. Aedeagus, in lateral view, curved smoothly from base, not becoming nar-
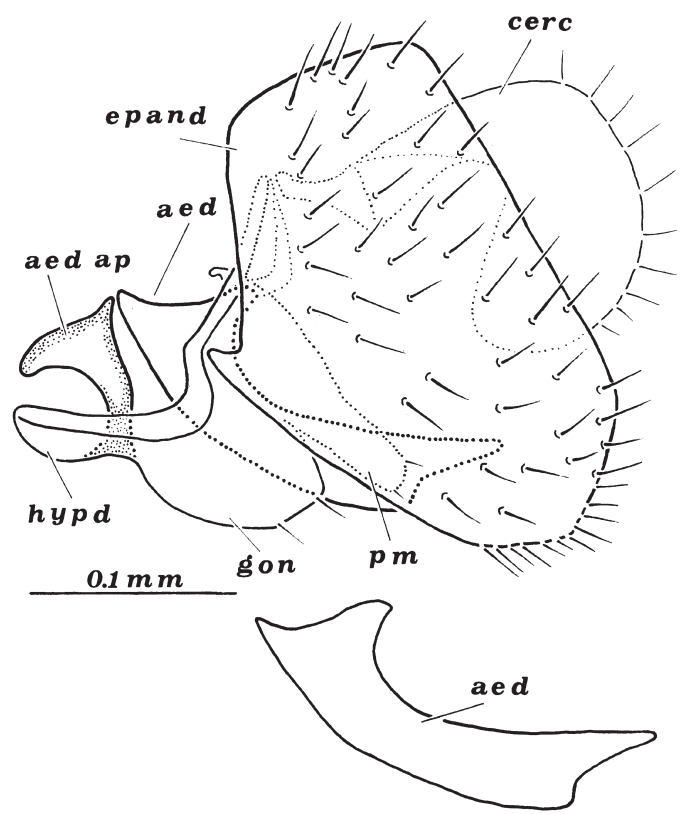

Fig. 3. Parochthiphila (Parochthiphila) inconstans (Becker), Malta - Male terminalia in lateral view and detail of aedeagus. Abbreviations: aed $=$ aedeagus, aed ap = aedeagal apodeme, cerc = cercus, epand = epandrium, gon = gonopod, hypd $=$ hypandrium, $\mathrm{pm}=$ paramere. 


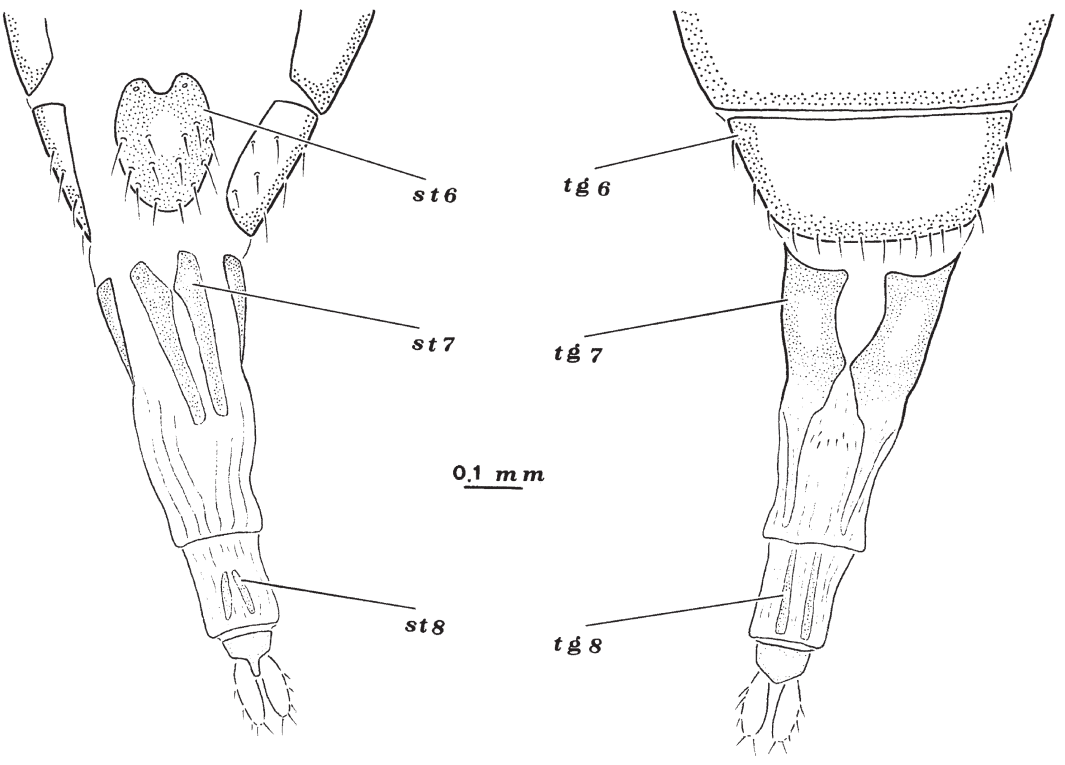

Fig. 4. Parochthiphila (Parochthiphila) inconstans (Becker), Malta. Female terminalia in ventral and dorsal view. Abbreviations: $\operatorname{tg}=$ tergite, st $=$ sternite . row towards apex where it ends shaped like a beak; tip bilobate in dorsal view.

Female terminalia (Fig. 4). Seventh sternite with 2 elongate symmetrical sclerites in median part. Seventh tergite with 2 large and elongate symmetrical sclerites becoming abruptly narrower in distal half; first half of tergite distinctly more sclerotized. Eighth sternite with 2 symmetrical elongate weak sclerites in the distal half, eighth tergite with 2 symmetrical elongate very weak sclerites; 2 pairs of strongly sclerotized suboval spermathecae present.

Type material. Lectotype $\hat{\jmath}$ (designated herein) in the Museum für Naturkunde der HumboldtUniversität zu Berlin. The specimen (right wing missing) is micropinned and double mounted; the 6 labels under the specimen are: Siala III 44850. (handwritten), Sammlung Dr. Th. Becker, TYPE (red label), card with male genitalia n. 6238, Holotypus Parochthiphila inconstans (Becker) (red label), Zool. Mus. Berlin. Paralectotypes 2 우 (designated herein) in the Museum fur Naturkunde der Humboldt-Universitat zu Berlin. The females are micropinned and on the same mount; the 4 labels under the specimens are: Siala III 44850. (handwritten), Sammlung Dr. Th. Becker, TYPE (red label), Zool. Mus. Berlin. The designation of a lectotype is necessary to fix the identity of the species for stability and to avoid confusion.
Additional material examined: Spain (Bale-

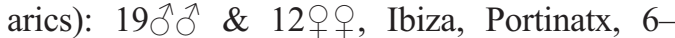
13.X.1983, J.C. Deeming legit (NMC); $5 \hat{\jmath}$ \&

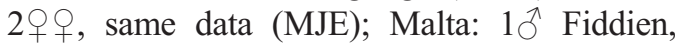
4.VII.1993, P. Gatt legit; 19 Rabat, Wied Ghomor, 17.VI.1992, M.J. Ebejer legit; 1ठ, Wied Qannotta, 7.VII.1987, M.J. Ebejer legit; 1今̄, Gozo, Gharb, Wied il-Mielah, 30.XI.1991, M.J. Ebejer legit; 1, Gozo, Ramla dunes, 23.IV.1992 P.Gatt legit; $2 \lesssim \widehat{\jmath}$, Salina, 31.V.1992, M.J. Ebejer legit; 1§̄, Mistra, 2.VI.2002, M.J.

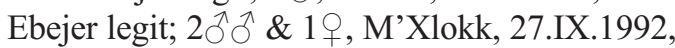

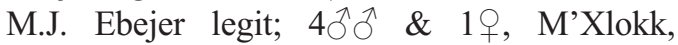

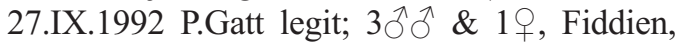
1.XI.1992, P.Gatt legit; 19, Ghadira, 9.IV.1993, M.J. Ebejer legit; 1 đ̄, Mgiebah, 26.V.1993, M.J. Ebejer legit; 1ठ, Bahrija, 13.VI.1993, M.J.

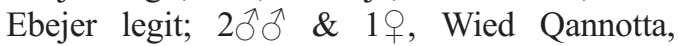
7.VII.1993, M.J. Ebejer legit; 1ठ઼, Buskett, 9.VII.1993, M.J. Ebejer legit; 1q, Fiddien, 10.X.1993, M.J. Ebejer legit; 3ठิ̄ 21.IX.1994, M.J. Ebejer legit; 1ð̄, Bahar icCaghaq, 4.X.1997, M.J. Ebejer legit. Oman: 1ð̄, hills S of Wadi Kabir 23 34'N 58 34'E, 310 m a.s.1., 26.III.1992 M.D. Gallagher legit; $1 \hat{\jmath}$, Shisr $18^{\circ} 15^{\prime} \mathrm{N} 53^{\circ} 39^{\prime} \mathrm{E}$, oasis, 12.XII.1996, M.D. Gallagher legit; Tunisia: $1 \hat{\jmath}$, Tabarka dunes, 13.V.1995, J.C. Deeming legit.

Comparative taxonomic notes. This species was described from Egypt (Becker 1903), but it 
appears to be widespread and common in several countries around the Mediterranean. It is easily distinguished from other known species of the subgenus Parochthiphila s.str. by the chaetotaxy of the mesonotum ( $1+2 \mathrm{dc}$ setae), by the pale grey frons having only in the female a broad black transverse band and by the male terminalia.

\section{New species, Parochthiphila (Euestelia) argentiseta Ebejer \& Raspi (Fig. 5, 6)}

Diagnosis. Body of male entirely silvery grey, but female abdomen with spots dorsally on tergites 4 and 5, and inferolaterally spots forming a black stripe from tergites 2 to 5 . Both sexes with black frontal band, palp and first flagellomere; mesonotum with $1+3$ dorsocentral setae. Tibiae and tarsi entirely yellow.

Description. of \& $\circ$. Length (excluding antenna): male $2.7 \mathrm{~mm}$, wing $2.6 \mathrm{~mm}$; female 2.6 $\mathrm{mm}$, wing $2.4 \mathrm{~mm}$.

Head. Higher than long, ratio 1.2:1, silver grey pollinose except for narrow but distinct black transverse band joining the anterior of 2 orbital setae. Extreme edges of band near to eye margin, shining, otherwise covered with black pollinosity. Numerous fine black setulae along this black band, mostly along its anterior margin; these continue at sides down orbital ridge to level of lunule, but remainder of frons bare. At narrowest distance between edge of lunule and eye margin is a small round silver grey spot in the shiny black stripe extending from lower orbit down to facial. Facial carina yellow and extending from this to each side as far as eye margin is a shining black band. Face and gena otherwise completely silver grey pollinose. Frons parallel-sided and as long as broad. Ocelli forming equilateral triangle on raised ocellar triangle which has convex lateral margins. Chaetotaxy: 2 strong orbitals, 1 pair ocellars and 1 pair of shorter postverticals, 1 internal and 1 external vertical. Postocular setulae in 2 rows, but only that adjacent to eye margin regular and complete. Eye oval, lying somewhat oblique. Antenna (Fig. 5a) with scape and pedicel in male pale yellow, darker and brownish in female, but in both sexes lightly covered in silver grey pollinosity; first flagellomere densely fine haired, completely black, only at base of arista yellow, in both sexes about 1.5 times longer than high. Arista with first two segments pale brown in female and pale yellow in male; remainder of arista in both sexes silvery white and short haired. Gena in profile narrow, about 0.25 height of eye (0.20 in female) and with a single row of short black setae along lower margin, 4 anteriorly and 2 posteriorly. Proboscis mainly yellow; palp black and lightly covered with silvery pollinosity and having a single seta at apex.

Thorax. Mesonotum with a pair of darker silvery grey vittae extending from anterior margin to scutellum. These are indistinct but for the pale vitta between them. Prescutellum distinct. At certain angles of light, pollinosity on mesonotum has a pale golden sheen. Chaetotaxy: 1 humeral, 1 posthumeral, 1 anterior which is about 1.3 times length of 1 posterior notopleural, 1 supra-alar, 1 postalar and 1 posterior intra-alar; $1+3$ dorsocentrals more or less equidistant from each other, 6 pairs of acrostichals in two very irregular rows ending well before hindmost dorsocentral; no prescutellar setae present. Scutellum uniformly silver grey pollinose with 1 pair of basal setae half length of subapical pair. Pleura silver grey pollinose as on mesonotum but without golden sheen and somewhat darker grey on hypopleuron and posterior part of sternopleuron. Mesopleural seta absent; 1 strong and 1 short sternopleural seta a little anterior from upper posterior angle of sternopleuron.

Wing. Hyaline with dense pale microtrichia giving it a slight milky white appearance. Veins, even at extreme base, very pale yellow, only at apices of $\mathrm{R}_{2+3}$ and $\mathrm{M}_{1+2}$ and costa adjacent to these a little brownish. Anterior crossvein oblique and placed just beyond middle of discal cell; posterior crossvein perpendicular to long axis of wing and about equal to distal section of $\mathrm{CuA} 1$. Haltere yellow.

Legs. Coxae and femora dark grey with silver grey pollinosity, less dense on coxae and absent on posterior surface of hind femur. Apical $5^{\text {th }}$ of femora bright yellow as is remainder of all tibiae and tarsi. All setulae on legs black.

Abdomen. Pale greyish brown mixed with silver pollinosity, more in female than male. Male abdomen without any markings. Female with round matt black spots dorsally on tergites 4 and 


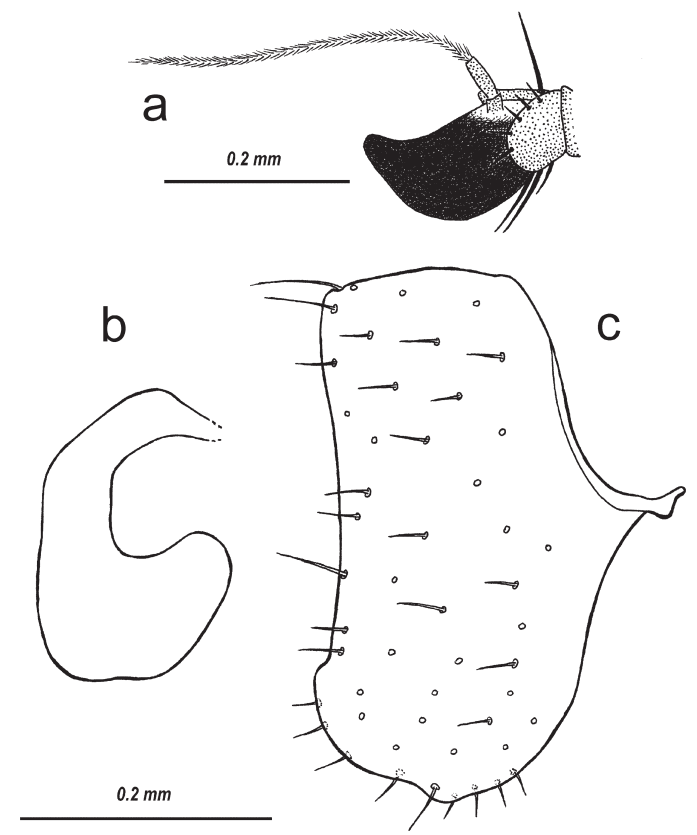

Fig. 5. Parochthiphila (Eustelia) argentiseta sp.n., Turkey. Male. - a. Antenna, outer aspect. - b. Cercus, lateral. - c. Epandrium, lateral.

5; on infero lateral margin with longitudinal shiny black spots that almost reach anterior and posterior margins of tergite thus appearing to form a longitudinal black stripe along the lateral margin of abdomen beneath.

Male terminalia. Epandrium with slightly irregular ventral margin, paramere and gonite very broad; aedeagus, in profile, right angled at base and with smoothly excavated ventral margin at apical $1 / 4$; basal part with posterior projection bent upwards; apex in dorsal view slightly trilobate (Fig. 5 b, c; Fig. 6 a-c).

Female terminalia not dissected. Ovipositor and elliptical cerci shining brown.

Type material. Holotype: $\widehat{\jmath}$, Turkey, Denizli, Aci Gol marsh, 4.VII.1997, M.J. Ebejer legit; Paratype, + , same data, both deposited in Amgueddfa Cymru National Museum Wales, Cardiff, UK.

Comparative taxonomic notes. The new species belongs to the $P$. (E.) coronata (Loew, 1858) group because it has 4 strong dorsocentral setae. Within this group only $P$. (E.) pallidovittata Tanasijtshuk, 1976 has the antenna with pedicel and the legs with all tibiae yellow, but the frontal band
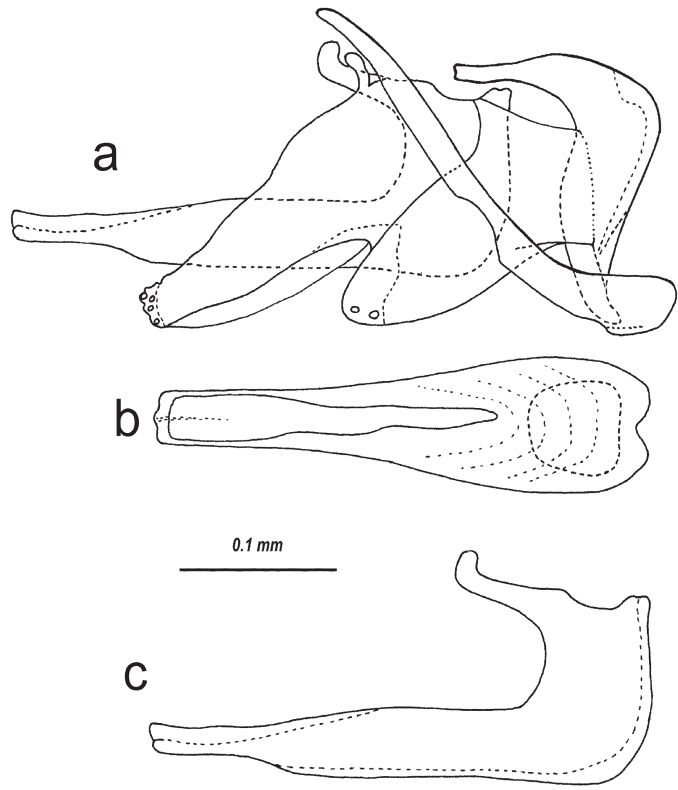

Fig. 6. Parochthiphila (Eustelia) argentiseta sp.n., Turkey. Male terminalia. - a. Hypopygium, lateral. - b.

Aedeagus, ventral - c. Aedeagus, lateral.

in this species is pale or absent and the male genitalia are very different. Within the coronata group also $P$. (E.) lucidifrons Tanasijtshuk, 1976 and $P$. (E.) kimmerica Tanasijtshuk, 1968 are similar to the new species, but both have a black antenna and the tibiae are dark in their middle section in kimmerica. Other differences are in the frontal band, the spots of abdomen and in the male genitalia. Although the male genitalia of the new species and those of kimmerica are at first glance quite similar, there are several important differences. The paramere in argentiseta has fewer setae at the apex, which is in line with the rest of the sclerite and not curved upwards; the gonite is also straight, whereas in kimmerica it is curved at its middle; the base of the aedeagus, where this meets the apical section at right angles, is twice as broad as the apical section, whereas in kimmerica the width of the two sections is almost the same; the cercus in argentiseta is a lot more curved. $P$. freidbergi Tanasijtshuk, 2004, recently described from Israel also has a pale arista (Tanasijtshuk 2004), but there are numerous differences in the colouration and chaetotaxy of the body, the shape of the head and details of the genitalia that separate the two species. 
Biology. The species was collected in summer like most other species of the genus Parochthiphila in the Mediterranean. Aci Gol is an inland marsh, about $150 \mathrm{~km}$ from the Mediterranean coast of Turkey. There were many species of gramineae growing in dense populations especially near surface water, but there were no trees in or near the marsh where the specimens were taken. The biology of this species is unknown, but in cases where the larvae of other species belonging to the genus Parochthiphila and Chamaemyia Meigen, 1803 are known, these are found between the leaf sheaths and secondary stalks of Gramineae infested by Pseudococcidae (Hemiptera), where they prey on mealybugs (Raspi 1983a, Raspi 2006).

Etymology. The name refers to the silvery white arista.

\section{List of species of Chamaemyiidae with new records}

\section{Parochthiphila (Euestelia) coronata}

(Loew, 1858)

Greece: 1 , , Sterea Elada, Fokida, Lidoriki, 300 m a.s.l., lakeside meadow, 8.V.1998, M.J. Ebejer legit; $1 \jmath^{\lambda}$, Macedonia, Thessaloniki, Limni Volvi, Langadikia, meadow, 10.V.1998, P. Gatt legit; Italy: $1 \widehat{\jmath}$, Sicily, Etna, Piano Provenzana, 1,800 m a.s.1., grassland \& Pinus, M.J. Ebejer legit; Spain: 10̃, Balearics, Mallorca, S’Albufera, Es Comú coastal dunes, Pinus, Juncus, Gramineae, 18.IV. 2001, M.J. Ebejer legit; $3 \partial^{\widehat{\partial}} \& 1$ 1 , s'Albufera, Son Bosc, marsh, dune grassland, Helichrysum, 24.V.2006, M.J. Ebejer legit; $1 \hat{\delta} \& 1$ ㅇ, same data, but 25.V.2006.

\section{Parochthiphila (Euestelia) frontella \\ (Rondani, 1874)}

Malta: 1§̄, Bahrija, 13.VI.1993, M.J. Ebejer legit; Turkey: $1{ }^{\lambda}$, Izmir, Kemalpasa, 600 m a.s.1., forest: oak, pine, 10.VII.1997, P. Gatt legit; $3 \hat{\jmath} \widehat{\partial}$ \& 1q, Izmir, Karaburun, Karapinar, sea coast, 11.VII.1997, M.J. Ebejer legit; 1ठ̃, Mugla, Dalyan, Iztuzu, saltmarsh, 14.VII.1997, P. Gatt legit;

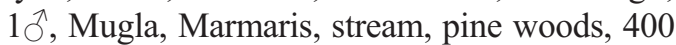
m a.s.1., 14.VII.1997, P. Gatt legit.

\section{Parochthiphila (Euestelia) kimmerica}

Tanasijtshuk, 1968

Greece: $1 \hat{\jmath} \& 1$, , Sterea Elada, Parnassos Mts, Eptalophos, 1,400 m a.s.1., meadow, conifers, 16.V.1998, P. Gatt legit; Turkey: $1 \hat{\jmath}$, Izmir, Bornova, Ege University, mixed grasses, 7.VII. 1997, J.C. Deeming legit.

\section{Parochthiphila (Euestelia) nigripes \\ (Strobl, 1900)}

Greece: 19, Macedonia, Thessaloniki, Limni Volvi, Langadikia, meadow, 10.V.1998, P. Gatt legit; 1ð̄, Sterea Elada, Parnassos Mts, Eptalophos, 1,400 $\mathrm{m}$ a.s.l., meadow, conifers, 16.V.1998, P. Gatt legit; 2 우, Sterea Elada, Itea, coastal garigue, 17.V.1998, M.J. Ebejer legit; Italy: 290 , Tuscany, Lucca, Bottaccio (Rio Guappero), 5.VII.2001 on Thyphoides arundinacea, D. Puccioni legit; $2 \widehat{\jmath}, \&$ \& 1 , Sicily, Piano delle Donne, 1,200 m a.s.1., pine forest, 5.VI.1999, M.J. Ebejer legit; 1ठ, Sicily, Catania, Randazzo, Rummolo, Flascio river, 7.VI.1999, J.C. Deeming legit; Lebanon: $2 \widehat{\jmath} \& 1$ ㅇ, $25 \mathrm{~km}$ SE Tripoli, Horsh Ehden Nature Reserve 1,300 m a.s.1., 29.V.- 3.VI.2001, J.C. Deeming legit; Turkey: $2 \widehat{\jmath} \& 2$ \& 9 Izmir, Karapinar coastal vegetation, 11.VII.1997, J.C. Deeming legit; 1 , Izmir, Kemalpasa $600 \mathrm{~m}$ a.s.1. oak \& pine forest, J.C. Deeming legit.

\section{Parochthiphila (Euestelia) transversa}

(Hennig, 1938)

Italy: $1 \hat{\jmath}$, Sicily, Etna, $3 \mathrm{~km}$ NW Milo, 1,200 m a.s.1., Castanea, Corylus, 5.VI.1999, M.J. Ebejer legit; 1ठ̄, Randazzo, Mte Spagnolo, 1,200 m a.s.l., grassland with Castanea, Acer \& Pinus, 6.VI.1999, M.J. Ebejer legit.

\section{Parochthiphila (Parochthiphila) spectabilis (Loew, 1858)}

Turkey: 1 , Denizli, Aci Gol, marsh, 4.VII.1997, P. Gatt legit.

Chamaemyia aridella (Fallén, 1823)

Italy: 1 q, Sicily, Randazzo, Mte Spagnolo, 1,200 $\mathrm{m}$ a.s.1., grassland with Castanea, Acer \& Pinus, 6.VI.1999, M.J. Ebejer legit; $8 \hat{\jmath}$ § 7 우 Etna, Piano Provenzana, 1,800 m a.s.1., grassland \& Pinus, M.J. Ebejer legit; Turkey: 1ठ, Mugla, Marmaris, stream, pine woods, $400 \mathrm{~m}$ a.s.l., 14.VII.1997, P. Gatt legit. 
Chamaemyia flavicornis (Strobl, 1902)

Italy: $14+9$ \& \& 1§, Tuscany, Lucca, Bottaccio (Rio Guappero), 11.VI.-20.VIII.2001, ex puparia, on Thyphoides arundinacea, D. Puccioni legit; 20 우, Bottaccio (LU), 28.VI-25.VIII. 2001, on Thyphoides arundinacea, D. Puccioni legit; 21 우, Bottaccio (LU), 23-28.VI.2001, on Phragmites australis; $2++\& \& 1 \hat{\jmath}$, Bottaccio (LU), 11.VI.2001, on Gramineae, Puccioni legit; 6웅, 15.V.2001 \& 4우, 9.IX.2001, Bottaccio (LU), on Thyphoides arundinacea D. Puccioni legit; Malta: 2̧ึô, Salina, 16.IV.1977, M.J. Ebejer legit; $3 \widehat{\jmath}$, Wied Qannotta, 5.IV.1992, M.J. Ebejer legit; $2 \widehat{\jmath} \&$ \& 1 , Fiddien, 11.V. 1992, M. J. Ebejer legit; 1 , Fiddien, 11.V.1992, M.J. Ebejer legit; 1ठ̄, Salina, 13.VII.1992, M.J.

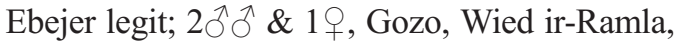
10.IV.1992, M.J. Ebejer legit; $2 \widehat{\jmath} \& 1$ ㅇ, Gozo, Ramla, 10.IV.1993, P. Gatt legit; $2 \widehat{\jmath}$, Fiddien, 10.X.1993, M.J. Ebejer legit; $4 \hat{\jmath} \& \& 1$ 으, Wied Qannotta, 20.II.1994, M.J. Ebejer legit; $3 \widehat{\jmath}$ ๙ \& 1ㅇ, Mgiebah, 24.IV.1994, M.J. Ebejer legit;

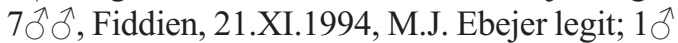
\& 1일. Mgiebah, 26.III.1995, M.J. Ebejer legit; $1 \widehat{\jmath} \& 1$, Mgiebah, 4.V.2001, B. Merz legit; $2 ㅇ$, Wied Qannotta, 4.XI.2001, M.J. Ebejer legit; Spain: $2 \circ+$, Balearics, Mallorca, S'Albufera, Ses Puntes marsh east, Tamarix \& Gramineae, 16.IV.2001, M.J. Ebejer legit; Tunisia: $1 \hat{\jmath} \& 1$, , Tabarka, Nefza-Zouaraa, 20.III. 2001, beach and fore dunes, P. Gatt legit.

\section{Chamaemyia geniculata (Zetterstedt, 1838)}

Italy: 1 , , Tuscany, Bottaccio (LU), 15.V.2001, on Thyphoides arundinacea, A. Raspi legit.

\section{Chamaemyia juncorum (Fallén, 1823)}

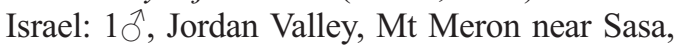
27.IV.1984, K.A. Spencer legit; Italy: $1 ð$, Sicily, Etna, Piano Provenzana, 1,800 m a.s.l., grassland \& Pinus, M.J. Ebejer legit; Lebanon: 1, $25 \mathrm{~km}$ SE Tripoli, Horsh Ehden Nature Reserve 1,300 m a.s.1., 29.V- 3.VI.2001, J.C. Deeming legit;

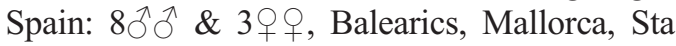
Margalida, Son Serra beach, Tamarix, Gramineae, Posidonia wrack, 19.IV.2001, M.J. Ebejer legit; Tunisia: 1ð̃, Tabarka, Ain Sobah dunes, Eucalyptus, pine, bog, 15.V.1995, M.J. Ebejer legit.
Chamaemyia polystigma (Meigen, 1830)

Greece: $1{ }^{\lambda}$, Crete, Nomós Lasithi, Plaka 12 km N of Aghios Nikolaos, Juncus \& grasses at beach, 15.X.1997, J.C. Deeming \& M.R. Wilson legerunt; 2 우, Crete, Nomós Lasithi, Lasithi plateau 800 m a.s.1., $2 \mathrm{~km}$ W Pinakiano, Juncus \& grasses, 14.-21.X.1997, J.C. Deeming \& M.R. Wilson legerunt; 19, Macedonia, Kilkis, Kateres, meadow, 400 m a.s.1., 12.V.1998, P. Gatt

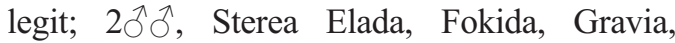
meadow, riverbank, 16.V.1998, M.J. Ebejer legit; $1 \widehat{\partial}$, same data, P. Gatt legit; Italy: $1 \hat{\jmath}$, Sicily, Etna, $3 \mathrm{~km}$ NW Milo, 1,200 m a.s.1., Castanea, Corylus, 5.VI.1999, M.J. Ebejer legit; $2 \widehat{\jmath} \widehat{\jmath}$, Sicily, Messina, Nebrodi, Troina, Lago d'Ancipa 1,100 m a.s.1., 8.VI.1999, M.J. Ebejer legit; Tunisia: $1 ð \& 1$ \& Gammarth, Dunes, 8.V.1995, P. Gatt legit; $1 \delta^{\lambda}$, Tabarka, Ain Sobah dunes, Eucalyptus, pine, bog, 15.V.1995, M.J. Ebejer legit.

Leucopis (Leucopis) argentata Heeger, 1848 Italy: 1ㅇ, Sicily, Siracusa, Noto Vendicari, coastal marsh and dunes, 10.VI.1999, M.J. Ebejer legit; Sicily, Catania, Randazzo, Lago di Gurrida 870 m a.s.1., Quercus \& Populus, 11.VI.1999, M.J. Ebejer legit; Malta: $1 \lesssim \& 4$ 우, Salina, 31.V.1992, M.J. Ebejer legit; 1옹 Salina, 13.VI.1992, M.J. Ebejer legit; 10 , same data, but P. Gatt legit; 2ððત, Salina, 23.VIII.1992, M.J. Ebejer legit; $1 \hat{\jmath}$, same data, but P. Gatt legit; $1 \hat{\jmath}$, Salina, 7.VII.1993, M.J. Ebejer legit; 2ðð \& $2 ㅇ$, Salina, 11.IV.1994, M.J. Ebejer legit; 1 우, Ghadira, 15.VI.1999, B. Merz legit; $2 \hat{\jmath}$, Salina,

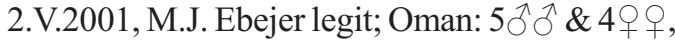

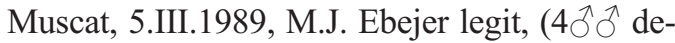
posited in NMC); Spain: 3 $\widehat{\partial}$ \& $\& 6$ 우, Balearics, Mallorca, s'Albufera, Es Forcadet, Canal del Sol \& Torrent de Muro, 17.IV.2001, M.J. Ebejer legit; $2 ㅇ$, S'Albufera, Es Cibollar marsh north, Tamarix, Juncus, Salicornia, 18.IV.2001, M.J. Ebejer legit; 1 , , S'Albufera, Sa Roca, vegetation near freshwater, Populus, 19.IV.2001, M.J. Ebejer legit; Tunisia: 1§̂, Bizerte, Ras Jebel, Ghar il Melh, 17.V.1997, M.J. Ebejer legit.

\section{Leucopis (Leucopis) artemisiae}

Tanasijtshuk, 1986

Turkey: 5 ð̊, Ödemis, Boz Dag, 2,000 m a.s.1., wooded gully, 9.VII.1997, J.C. Deeming legit. This species was described from Primore in 
south-eastern Russia. It is similar to L. rufithorax Tanasijtshuk, 1958 and L. auraria Tanasijtshuk, 1961 but $L$. auraria has yellow palp and pedicel of antenna. In L. artemisiae there are a number of significant differences in the genitalia compared to auraria. The series from Turkey agrees in every detail with the illustration in Tanasijtshuk (1986). It is recorded for the first time from the Mediterranean.

Leucopis (Leucopis) auraria Tanasijtshuk, 1961 Italy: $19 \hat{\jmath} \& 6$ 우우, Tuscany, Pisa, 10.VI30.VII.1995, ex puparia on Populus alba infested by Chaitophorus populeti \& C. populialbae, Sabrina Ambroselli legit; Malta: $6 \widehat{\jmath}^{\lambda}$, Salina, 13.VII.1992, M.J. Ebejer legit; 19, Buskett, 9.VII.1993, M.J. Ebejer legit.

\section{Leucopis (Leucopis) formosana Hennig, 1938}

Cyprus: $2 \hat{\jmath} \widehat{\jmath}$, Akrotiri Peninsula, Akrotiri saltmarsh, dunes \& pine wood, 30.IV.2002, M.J.

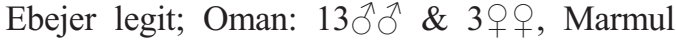
Desert Agricultural Project, 24.XI.1992, J.C. Deeming legit.

\section{Leucopis (Leucopis) gloriae Raspi, 1985}

Italy: Liguria, 1へ̄, 11.IX.1994; 3 우 10.X.1994, ex puparia inside galls of Forda marginata on

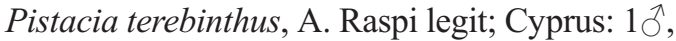
Diarizos valley, $70 \mathrm{~m}$ a.s.l., Nikoklela, stream \& pasture, 23.IV.2002, M.J. Ebejer legit; Israel: $1 \delta^{\Uparrow}$, Jordan Valley, Mt Meron near Sasa, 27.IV.1984, K.A. Spencer legit.

The middle section of the distiphallus in the specimen from Cyprus does not have as much swelling of the ventral bulge as illustrated in the photomicrographs of the original description (Raspi 1983b). Otherwise this specimen fits the description well and the genitalia are very similar.

\section{Leucopis (Leucopis) glyphinivora}

Tanasijtshuk, 1958

Italy: 2ðð, Sicily, Alcamo (TP), 8.VII.1994; Lebanon: 5 ふૈર \& 10우, 25 km SE Tripoli, Horsh Ehden Nature Reserve 1,300 m a.s.l., 29.V.-3.VI.2001, J.C. Deeming legit; Malta: $1{ }^{\lambda}$, Wied Qannotta, 31.VIII.1978, P. Gatt legit; $10^{\top}$ \& $2 ㅇ$ 으, Gozo, Ta’ Cenc, 1.IV.1994, M.J. Ebejer legit; Spain: $3{ }^{\lambda}{ }^{\wedge} \&$ \& 3 우, Balearics, Ibiza, Sant Llorenç de Bolafi, Can Savi, on aphid infested stems of Foeniculum vulgare, 31.V.2006, M.J. Ebejer; the same stems with aphids were collected and the following adult flies emerged as follows: $3 \hat{\jmath}$ \& $\& 1$,, 16. VI.2006; 4우, 17.VI. 2006; 1ㅇ, 18.VI.2006; Tunisia: 1ठ, Jendouba, Oued Mellegue, 11.V.1995, P. Gatt legit; 4ठえ \& $3 ㅇ$, Fernana, meadow, stream, pine wood, 14.V.1995, M.J. Ebejer legit; Turkey: $1 \delta^{\Uparrow} \& 1$, Isparta, Egirdir, $12 \mathrm{~km}$ west, stream in meadow, 5.VII.1997, M.J. Ebejer legit.

Tanasijtshuk (1986) gives a long list of aphid species where these have been prey to this polyphagous species of Leucopis.

Leucopis (Leucopis) grunini Tanasijtshuk, 1979 Cyprus: $29+$, Pano Lefkara, $595 \mathrm{~m}$ a.s.1., ruderal vegetation, 26.IV.2002, M.J. Ebejer; $1 \hat{\delta} \& 3$ 우, $7 \mathrm{~km}$ NE of Kouklia, oak \& Pistachia forest, 350 $\mathrm{m}$ a.s.1., 27.IV.2003, M.J. Ebejer legit; Italy: $1 \overbrace{}^{\top}$, Sicily, Giuliana (PA), ex puparium on gall of Pistacia lentiscus; $1 \hat{\jmath}$, Sicily, Cinisi (Furi stream) (PA), ex puparium on gall of Pistacia terebinthus, R. Lo Duca legit; Lebanon (at that time part of Syria): $3 \widehat{\jmath}$, "Syria", Beirut, in the Bezzi Collection of the Museum of Natural History in Milan.

\section{Leucopis (Leucopis) kerzhneri}

Tanasijtshuk, 1970

Greece: $1 \widehat{\partial}$, Sterea Elada, Itea, coastal garigue, 17.V.1998, P. Gatt legit; Tunisia: $1 \hat{O}^{\wedge} \& 1$,

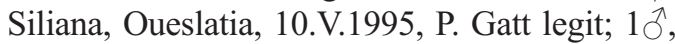
Siliana, Lagsab, 11.V.1995, P. Gatt legit; 10 \& 1ㅇ, Tabarka, Dunes, 12.V.1995, P. Gatt legit; 10 $\& 1$, Fernana, meadow, stream, pine wood, 14.V.1995, M.J. Ebejer legit; 19, Menzel Bourguiba, 16.V.1995, P. Gatt legit.

\section{Leucopis (Leucopis) monticola}

Tanasijtshuk, 1961

Turkey: $2 \hat{\jmath}$, Egirdir, $12 \mathrm{~km}$, west, stream in meadow, 5.VII.1997, M.J. Ebejer legit.

\section{Leucopis (Leucopis) pallidolineata}

Tanasijtshuk, 1961

Greece: 1 , , Crete, Nomós Lasithi, near Kalamafka 500m, swept from irrigated Sorghum halpense in olive grove, 14.-21.X.1997, J.C. Deeming \& M.R. Wilson legerunt; Turkey: $1{ }^{\lambda}$, Isparta, Beysehir lake, marsh \& mixed coniferous forest, 6.VII.1997, M.J. Ebejer legit; 1ठ̄, same data, P. Gatt legit. 
Leucopis (Leucopis) palumbii Rondani, 1872 Greece: $2 \widehat{\jmath}$, Crete, Agia Pelagia, 16.X. 1994, P. Gatt legit; 1 , Crete, Nomós Lasithi, Plaka 12 km $\mathrm{N}$ of Aghios Nikolaos, Juncus \& grasses at beach, 15.X.1997, J.C. Deeming \& M.R. Wilson legerunt; Spain: 4우, Balearics, Mallorca, s'Albufera, Camí des Polls, on leaves of Ulmus near gall of Eriosoma sp. 21.V.2006; 1今, emerged from the same gall 10.VI.2006; 2 more galls were collected on 28.V.2006, but only one yielded adults: 2 우, 7.VI.2006; 5ภへ \& 6우우, 9.-12.VI.2006; 6へึ \& 7우, 13.-15.VI.2006, all M.J. Ebejer legit.

Raspi (1988) gives a detailed account of the life history of this species and the aphid hosts (Pemphigidae: Eriosomatinae and Fordinae) that form galls on young leaves respectively on species of Ulmus and Pistacia in the spring.

\section{Leucopis (Leucopis) revisenda}

Tanasijtshuk, 1970

Italy: $4 \hat{\jmath}$ đ 3 q $q$, Sicily, Nebrodi, Troina, Lago d'Ancipa, 1,100 m a.s.1., 8.VI.1999, M.J. Ebejer legit; Malta: 1\%, Ghadira, 4.V.2001, B. Merz legit.

These specimens fit the description and illustrations perfectly. In Europe, it is known from the South of France.

\section{Leucopis (Leucopis) rufithorax}

Tanasijtshuk, 1958

Italy: $13 \precsim \widehat{\jmath}$, Tuscany, Pisa, 10.VI.-30.VII.1995, ex puparia on Populus alba infested by Chaitophorus populeti \& C. populialbae, S. Ambroselli legit; $66 \hat{\jmath} \hat{\jmath} \&$ 우, Tuscany, Pisa, 19.VI.1.VIII.2001, ex puparia on Populus alba infested by Chaitophorus populeti \& C. populialbae, D. Puccioni legit.

Acknowledgements. We are grateful to Paolo Giannotti, of Dep. Coltivazione e Difesa delle Specie Legnose "G. Scaramuzzi", Sezione di Entomologia agraria, for valuable assistance in preparing the photographic documentation and to Paul Gatt, Malta for generously making available to us his collection of Chamaemyiidae. AR thanks Joachim Ziegler, Museum für Naturkunde, Institut für Systematische Zoologie, Humboldt-Universität zu Berlin, Germany for the loan of types and Fabrizio Rigato of Milan Museum of Natural History for valuable assistance in the
Bezzi collection. MJE is grateful to Adrian Plant and the authorities of Amgueddfa Cymru National Museum Wales, Cardiff, UK for facilities and use of the records of Chamaemyiidae in the collections.

\section{References}

Becker, T. 1903: Agyptische Dipteren. — In Mitteilungen aus dem Zoologischen Museum in Berlin. II. Band, 3. Heft. R. Friedlander \& Sohn, Berlin; 67-195 + 5 Tafeln.

Beschovski V. L. \& Merz, B. 1998: Contribution to the knowledge of the Chamaemyiidae (Diptera), with particular reference to the fauna of Switzerland. Mitteilungen der Schweizerischen Entomologischen Gesellschaft. — Bulletin de la Société Entomologique Suisse 71: 83-106.

Carles-Tolrá M. 2002: Chamaemyiidae p.151. — In: Catálogo de los Diptera de España, Portugal y Andorra (Insecta). Monografias S.E.A. Volume 8. Sociedad Entomológica Aragonesa, Zaragoza. 323 pp.

Frey R. 1958: Zur Kenntnis der Diptera brachycera p.p. der Kapverdischen Inseln. - Commentationes Biologicae, XVIII n. 4: 1-61.

Gaimari S. D. 2007: Fauna Europaea: Diptera, Chamaemyiidae. Version 1.3. [www document]. — URL http://www.faunaeur.org.

Raspi A. 1983a: Contributi alla conoscenza dei Ditteri Camemiidi. II. Note etologiche e morfologiche su Leucopis interruptovittata Aczél, Chamaemyia flavipalpis (Haliday) e Parochthiphila coronata (Loew) (Diptera, Chamaemyiidae) della Toscana litoranea. — Frustula Entomologica, Pisa, n.s., VI (XIX): 103-139.

Raspi A. 1983b: Contributi alla conoscenza dei Ditteri Camemiidi. III. Considerazioni sulla Leucopis palumbii Rondani e descrizione di Leucopis gloriae n.sp. Frustula Entomologica, Pisa, n.s., VI(XIX): 351-367.

Raspi A. 1988: Contributi alla conoscenza dei Ditteri Camemiidi. V. Su alcune specie del genere Leucopis viventi a spese di afidi eriosomatidi. - Frustula Entomologica, Pisa, n.s., XI (XXIV): 75-118.

Raspi A. 1995: Chamaemyiidae. In: Nartshuk, E. P., Papp, L., Raspi, A. \& Rivosecchi, L. Diptera Nerioidea, Diopsoidea, Lauxanioidea. — In: A. Minelli, A. Ruffo, S. \& La Posta, S. (eds.), Checklist delle specie della fauna italiana, 73, Calderini, Bologna.

Raspi A. 2006: On the identity of Parochthiphila (Euestelia) frontella (Diptera Chamaemyiidae). - Bollettino della Società Entomologica Italiana, 138 (3):249-254.

Tanasijtshuk, V. N. 1986: Chamaemyiidae. — In: Fauna of the USSR n.s., n 134. Diptera 14(7). Nauka, Leningrad, 1-335 pp + 1-16 pls. [In Russian].

Tanasijtshuk, V. N. 2004: A new species of Parochthiphila (Diptera: Chamaemyiidae) from Israel and Egypt. Israel Journal of Entomology, 34: 29-33. 